\title{
Correction to: Organic matter degradation state affects dissimilatory nitrate reduction processes in Knysna estuarine sediment, South Africa
}

\author{
Yongkai Chang ${ }^{1} \cdot$ Lijun Hou $^{1} \cdot$ Dengzhou Gao ${ }^{1} \cdot$ Min Liu $^{2} \cdot$ Cheng Liu ${ }^{1}$ Zongxiao Zhang ${ }^{1}$
}

Published online: 6 August 2021

(c) Springer-Verlag GmbH Germany, part of Springer Nature 2021

\section{Correction to: Journal of Soils and Sediments https://doi.org/10.1007/s11368-021-02925-y}

In the original version of the article, the authors omitted to mention the institution that provided the research permit in South Africa and relevant funding support. The correct Acknowledgements and Funding sections are noted below.

Acknowledgements Thanks to Dr. Jianhong Xue for guidance and help in conducting the experiments. We also thank Dr. Jianli Guo for assistance with language editing on the earlier version of this draft. Thanks are given to the editors and anonymous reviewers for constructive comments and suggestions on this manuscript. We acknowledge the Department of Environmental \& Geographical Science, University of Cape Town, for assistance with fieldwork and logistics. The work was conducted under the South African National Parks research permit number: MEAD-ME/2018-007.

Funding This work was supported by the Natural Science Foundation of China (grant numbers: 41761144062, 41725002, 42030411, and 41730646) and by the National Research Foundation of South Africa (grant number: 110776). It was also funded by Chinese National Key Programs for Fundamental Research and Development (nos. 2016YFA0600904 and

The original article can be found online at https://doi.org/10.1007/ s11368-021-02925-y.

Dengzhou Gao

dzgao@sklec.ecnu.edu.cn

$\triangle$ Min Liu

mliu@geo.ecnu.edu.cn

1 State Key Laboratory of Estuarine and Coastal Research, East China Normal University, 500 Dongchuan Road, Shanghai 200241, China

2 Key Laboratory of Geographic Information Science of the Ministry of Education, College of Geographical Sciences, East China Normal University, 500 Dongchuan Road, Shanghai 200241, China
2016YFE0133700) and Fundamental Research Funds for the Central Universities.

The original article has been corrected.

Publisher's Note Springer Nature remains neutral with regard to jurisdictional claims in published maps and institutional affiliations. 